\title{
Evaluating the Effectiveness of the Two Training Methods for Increasing Nursing Students' Knowledge Level on Sexually Transmitted Diseases
}

\author{
Hemşirelik Öğrencilerinin Cinsel Yolla Bulaşan Hastalıklar Konusunda Bilgi \\ Düzeylerini Arttırmaya Yönelik İki Eğitim Yönteminin Etkinliğinin \\ Değerlendirilmesi
}

\author{
Gönül KURT $T^{l}$, Semra AÇIKSÖZZ ${ }^{2}$, Hamide ARSLAN
}

\begin{abstract}
Objective: The aim of this study was to evaluate the effectiveness of the two different methods of education in order to increase the awareness and the knowledge of nursing students about sexually transmitted diseases (STDs). Methods: This interventional study is carried out by first and second year students in a nursing school. In the application phase of the study, peer education was given to first year students $(\mathrm{n}=123)$ and second year students $(\mathrm{n}=77)$ were trained by an expert educator accompanied by an educational brochure. The data were collected by using Participant Description Form and Information Form on Sexually Transmitted Diseases. Data were collected before the training and also after one month following the training. The SPSS 22.0 package software program was used for the evaluation of the data obtained from the study. Data were analyzed by Mann-Whitney-U test, Chi-square test and Wilcoxon Signed Ranks test. Results: Within the scope of the study, it was determined that students in both groups had mid-level knowledge regarding STDs before the education and there was no statistically significant difference between groups ( $>0.05)$. Before the education, students in both groups stated that STDs are transmitted through blood in the highest rate, after sexual intercourse. At the same time, students in the peer training group reported that the people who are polygamous are at the highest risk of STDs, while students in the brochure+expert training group reported that sex workers are at the highest risk of getting STDs. After the education, knowledge scores regarding STDs of the students who were trained by an expert educator with an educational brochure was found to be higher than those who were given peer training $(\mathrm{p}<0.001)$. Conclusion: After the education, the level of knowledge regarding STDs of the students who had brochure+expert training were higher when compared to the students who had peer training. It was found that brochure+expert training is an effective method for increasing the knowledge and awareness of students regarding STDs. Most of the students in both education groups knew the groups that are at risk for STDs, and knew one of the transmission methods apart from sexual intercourse before the training. Training of the young using different and proven methods to increase their knowledge about STDs will ensure the protection and improvement of sexual and reproductive health.
\end{abstract}

Keywords: Peer training, brochures, expert training, sexually transmitted diseases.

\section{ÖZET}

Amaç: $\mathrm{Bu}$ araştırma ile hemşirelik öğrencilerinin cinsel yolla bulaşan hastalıklar $(\mathrm{CYBH})$ konusunda bilgi düzeylerinin ve farkındalıklarının arttırılmasına yönelik uygulanan iki farklı eğitim yönteminin etkinliğini değerlendirmek amaçlanmıștır. Yöntem: Müdahale tipindeki bu araștırma, bir hemșirelik yüksekokulunda öğrenim görmekte olan 1. ve 2. sınıf hemşirelik öğrencileri ile yürütülmüştür. Araştırmanın uygulama aşamasında 1. sınıf öğrencilerine akran eğitimi ( $\mathrm{n}=123)$, 2. sınıf öğrencilerine ise broşür eşliğinde uzman bir eğitimci tarafından eğitim $(\mathrm{n}=77)$ verilmiştir. Araştırma verilerinin toplanmasında Katılımcı Tanılama Formu ve Cinsel Yolla Bulaşan Hastalıklara İlişkin Bilgi Formu kullanılmıştır. Araştırma verileri eğitim öncesi ve eğitim verildikten bir ay sonra toplanmıștır. Araştırma verileri SPSS 22.0 paket programı kullanılarak değerlendirilmiștir. Verilerin analizinde Mann Whitney U testi, Ki-kare testi ve Wilcoxon Signed Ranks testi kullanılmıştır. Bulgular: Araştırma kapsamında her iki eğitim grubundaki öğrencilerin eğitim öncesi CYBH konusunda bilgi düzeylerinin orta düzeyde olduğu ve CYBH ilişkin bilgi düzeyi açısından gruplar arasında fark olmadığı saptanmıştır (p>0,05). Eğitim öncesi, her iki eğitim grubundaki öğrencilerin en yüksek oranda CYBH'nin cinsel ilişki dışında kan yolu ile bulaştığını bildikleri belirlenmiştir. Aynı zamanda eğitim öncesi akran eğitimi grubundaki öğrenciler CYBH açısından en yüksek oranda çok eşli olan kişilerin risk altında olduğunu, broşür+uzman eğitimi grubundaki öğrenciler ise en yüksek oranda seks işçilerinin risk altında olduğunu bildirmiştir. Eğitim sonrası ise broşür eşliğinde uzman eğitimci tarafindan eğitim verilen öğrencilerin, akran eğitimi verilen öğrencilere göre CYBH konusunda bilgi düzeylerinin daha yüksek olduğu saptanmıştır (p<0,001). Sonuç: Broşür+uzman eğitimi verilen öğrencilerin eğitim sonrası CYBH konusundaki bilgi düzeyleri akran eğitimi verilen öğrencilere göre daha yüksektir. Öğrencilerin CYBH'ye ilişkin bilgi düzeylerini ve farkındalıklarını arttırmada broşür+uzman eğitimi vermenin etkili bir yöntem olduğu bulunmuştur. Her iki eğitim grubundaki öğrencilerin çoğunun eğitim öncesinde CYBH açısından risk altında olan grupları ve cinsel ilişki dışında bulaşma yollarından birini bildikleri saptanmıştır. Gençlerin CYBH konusunda bilgi düzeylerini arttırmada farklı ve etkinliği kanıtlanmış yöntemler ile eğitimlerin verilmesi, cinsel sağlık ve üreme sağlığının korunmasını ve geliştirilmesini sağlayacaktır.

Anahtar Kelimeler: Akran eğitimi, broșür, uzman eğitimi, cinsel yolla bulaşan hastalıklar.

Received / Geliş tarihi: 01.09.2020, Accepted / Kabul tarihi: 16.11.2020

${ }^{1}$ Sağlık Bilimleri Üniversitesi, Gülhane Hemşirelik Fakültesi, Ankara

${ }^{2}$ Sağllk Bilimleri Üniversitesi, Hamidiye Hemşirelik Fakültesi, İstanbul

${ }^{3}$ Marmara Üniversitesi, Sağlık Bilimleri Fakültesi, Hemşirelik Bölümü, İstanbul

*Address for Correspondence / Yazıșma Adresi: Gönül KURT, Sağlık Bilimleri Üniversitesi, Gülhane Hemşirelik Fakültesi, Gülhane Külliyesi, Emrah Mahallesi, General Doktor Tevfik Sağlam Caddesi, 06010 Etlik, Keçiören, Ankara-Türkiye, E-mail: f.gonul@yahoo.com

Kurt G, Açıksöz S, Arslan H. Evaluating the Effectiveness of the Two Training Methods for Increasing Nursing Students' Knowledge Level on Sexually Transmitted Diseases. TJFMPC, 2021;15(1): 33-41. DOI: $10.21763 /$ tjfmpc.788356 


\section{Gİiş̧}

Cinsel yolla bulaşan hastalıklar (CYBH), bakteri, virüs ve parazit gibi patojenlerin neden olduğu, genellikle cinsel ilişki sonrası akut semptom ve bulgularla başlayıp sıklıkla kronikleşen enfeksiyon hastalıklarıdır. ${ }^{1,2}$ CYBH'ye neden olan 30'dan fazla patojen bulunmaktadır. Bunlardan en yüksek insidansa sahip olan klamidya, sifiliz, gonore ve trikomonasın tedavisi mümkünken; İnsan İmmun Yetmezlik Virüsü (Human Immunodeficiency Virüsü-HIV), Human Papilloma Virüsü (HPV), Herpes Simpleks Virüsü (HSV) ve Hepatit B virüsünün kesin bir tedavisi yoktur. ${ }^{3} \mathrm{Bu}$ patojenler sıklıkla korunmasız cinsel ilişki ile bulaşmaktadır. Bununla birlikte enfekte kan transfüzyonu ve organ nakli ile kişiden kişiye, gebelik döneminde, doğum esnasında ve emzirme ile de anneden bebeğe bulaşabilmektedir. ${ }^{4}$

Dünyada her gün çoğu gelişmekte olan ülkelerde olmak üzere bir milyondan fazla kişiye cinsel yolla enfeksiyon bulaştığı ve her yıl 376.4 milyon tedavi edilebilir CYBH ortaya çıktığı tahmin edilmektedir. ${ }^{3} \mathrm{Bu}$ hastalıkların en yüksek oranda 20 24 yaşları arasında, ikinci sıklıkta ise 15-19 yaş

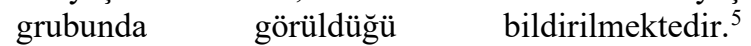
Amerika Birleşik Devletleri Hastalık Kontrol ve Korunma Merkezine (CDC) göre yeni tanı konulan CYBH'nin yarısının 15-24 yaşları arasındaki gençlerde görüldüğü ve cinsel olarak aktif her dört genç kadından birinin klamidya veya HPV gibi CYBH'ye yakalandığ 1 tahmin edilmektedir. ${ }^{6} \mathrm{Bu}$ nedenle günümüzde $\mathrm{CYBH}$, gençlerde önemli bir halk sağlığı sorunu haline gelmiştir. Gençlerde CYBH'nin daha yüksek oranda görülmesinin temel nedeninin, CYBH ve korunma konusunda bilgi eksikliği olduğu belirtilmektedir. ${ }^{7}$ Ayrıca özellikle gelişmekte olan ülkelerde cinsel eğitim programlarının yetersiz olması, erken yaşta cinsel ilişki ve cinsel eş sayısının fazla olması, korunmasız cinsel ilişski gibi nedenlerden dolayı gençlerde CYBH'nin daha fazla görüldüğü bildirilmektedir. ${ }^{8-10}$ Bununla birlikte gençlerin sağlık hizmetlerine ulaşamamaları, CYBH konusunda sağlık hizmeti aldıklarında utanç duymaları, kişisel bilgilerinin gizli tutulmayacağını düşünmeleri, maddi imkânlarının yetersiz olması, muayene saatleri ve ders saatlerinin çakışması gibi nedenlerin de etkili olduğu belirtilmektedir. ${ }^{6}$ Tüm bu nedenlere bağlı olarak gençlerde CYBH'nin yaygınlaşması ve istenmeyen gebelikler, istemli düşükler, riskli cinsel davranışlar, erken yaşta çocuk sahibi olma gibi üreme sağlığı sorunları ortaya çıkabilmektedir. ${ }^{7,11}$

CDC tarafindan yayınlanan $\mathrm{CYBH}$ k1lavuzunda, bu hastalıklardan korunmada risk grubunu oluşturan kişilerin değerlendirmesinin yapılması, eğitim ve danışmanlık sağlanması önerilmektedir. ${ }^{12} \mathrm{Bu}$ kapsamda $\mathrm{CYBH}$ açısından toplumda yüksek risk gruplarından biri olan gençlerin bilgi düzeylerinin ve farkındalıklarının arttırılması amaciyla yapılacak eğitimler, riskli cinsel davranışların azaltılması, erken tanı ve tedavi edilmesi açısından önemlidir.

$\mathrm{Bu}$ araştırma ile hemşirelik öğrencilerinin CYBH'ye ilişkin bilgi düzeylerini belirlemek ve $\mathrm{CYBH}$ konusunda bilgi düzeylerinin ve farkındalıklarının arttırılmasına yönelik uygulanan akran eğitimi ve broşür eşliğinde uzman bir eğitimci tarafından verilen eğitimin etkinliğini değerlendirmek amaçlanmıştır.

\section{YÖNTEM}

\section{Araştırmanın Türü}

$\mathrm{Bu}$ araştırma müdahale tipi bir çalışmadır.

\section{Evren ve Örneklem}

Araştırma, Şubat-Mayıs 2015 tarihleri arasında bir üniversitenin hemşirelik yüksekokulunda (HYO) yürütülmüştür. Araştırmanın evrenini, HYO'da eğitim görmekte olan 1 . ve 2 . sınıf hemşirelik öğrencileri $\quad(n=220 ; 1 . \quad$ sinıf $=132,2 . \quad$ sinıf $=88)$ oluşturmuştur. HYO'daki eğitim-öğretim programı doğrultusunda 1. ve 2. sinıftaki öğrencilerin henüz CYBH konusunda herhangi bir eğitim almaması nedeniyle bu öğrenciler araştırma kapsamına dahil edilmiştir. Araştırmada örneklem seçimi yapılmamış olup, gönüllü olarak araştırmaya katılmayı kabul eden 200 öğrenci (\%91) çalışma kapsamına alınmıştır. Araştırmaya katılmaya gönüllü olmayan ve araştırmanın yapıldığı tarihlerde devamsız olan 20 öğrenci örneklem dişı bırakılmıştır.

\section{Veri Toplama Araçları}

Verilerin toplanmasında "Katılımcı Tanılama Formu" ve "Cinsel Yolla Bulaşan Hastalıklara İlişkin Bilgi Formu” kullanılmıştır.

Katılımcı Tanılama Formu: Öğrencilerin tanıtıcı özelliklerini içeren katılımcı tanılama formu araştırmacılar tarafından ilgili literatür doğrultusunda oluşturulmuştur. ${ }^{13,14}$ Katılımcı tanılama formunun ilk bölümünde; öğrencilerin yaş, aile tipi, ebeveynlerinin eğitim durumu gibi sosyodemografik özelliklerini içeren sorular yer almaktadır. Formun ikinci bölümü ise CYBH'nin belirtileri, bulaşma yolları, risk faktörleri ve CYBH'den korunma yöntemleri gibi CYBH'ye ilişkin bilgilerini belirlemeye yönelik sorulardan oluşmaktadır.

Cinsel Yolla Bulaşan Hastalıklara İlişkin Bilgi Formu: $\mathrm{Bu}$ form, öğrencilerin CYBH'ye ilişkin bilgi düzeylerini belirlemek amacıyla 
araştırmacılar tarafından literatür doğrultusunda oluşturulmuştur. 7,13,14 Formda, CYBH'ye ilişkin bilgi düzeyini sorgulayan 30 ifade bulunmaktadır. Formdaki her bir ifade "Doğru", "Yanlış", "Bilmiyorum" şeklinde işaretlenmektedir. Formun değerlendirilmesinde doğru yanıtlanan ifadelere "1", "Bilmiyorum" şeklinde yanıtlanan veya yanlıș cevaplara " 0 " puan verilmiştir. Formun tamamından alınabilecek en düşük puan 0 ve en yüksek puan 30'dur. Cinsel Yolla Bulaşan Hastalıklara İlişkin Bilgi Formunun eğitim öncesi dönemde cronbach alfa değeri 0,90 , eğitim sonrası dönemde ise 0,80 olarak hesaplanmıştır. Formdan alınacak puanın yüksek olması, CYBH'ye ilişkin bilginin yüksek düzeyde olduğunu göstermektedir. $\mathrm{Bu}$ form, örneklem kapsamındaki her iki gruptaki öğrencilere eğitim öncesi (ön test) ve eğitimden bir ay sonra (son test) uygulanmıştır.

\section{Verilerin Toplanması ve Araştırmanın Uygulama Aşaması}

Araştırma iki grup üzerinde yürütülmüştür. Araştırma kapsamında CYBH konusunda, 1. sınıf öğrencilere akran eğiticiler tarafından akran eğitimi (akran eğitimi grubu), 2. sınıf öğrencilere ise sorumlu araştırmacı tarafından broşür eşliğinde eğitim (broşür+uzman eğitimi grubu) verilmiştir. Sınıflara hangi yöntem kullanılarak eğitim verileceği ise kura çekilerek belirlenmiştir.

\section{Uygulama Öncesi Hazırlık Aşaması}

\section{Akran Ĕgiticilerin Ĕgitimi}

Araştırmanın uygulama aşamasında gönüllü olarak yer almak isteyen, iletişim ve sunum becerileri iyi olan, HYO 4. sınıfta öğrenim gören beş öğrenci akran eğitici olarak seçilmiştir. Akran eğiticilere, uygulama öncesi $\mathrm{CYBH}$, iletişim becerileri ve sunum teknikleri konularında sorumlu araştırmacı tarafından eğitim verilmiştir. Sorumlu araştırmacı kadın sağlığı alanında uzman bir öğretim elemanı olup, T.C. Sağlık Bakanlığı tarafından verilen Üreme Sağlığı ve Aile Planlaması Uzman Eğitici ve ayrıca Eğitim Becerileri sertifikalarına sahiptir. Akran eğiticilerin eğitimi sırasında T.C. Sağlık Bakanlığı ve Birleşmiş Milletler Nüfus Fonu (UNFPA) tarafından hazırlanan eğitim modülleri kullanmıştır. ${ }^{15,16}$ Akran eğiticilerin eğitimi ortalama 85-90 dakika sürmüştür. Ayrıca akran eğiticilere verilen eğitimin yeterliliğini değerlendirmek amacıyla eğitim öncesi ve sonrası cinsel yolla bulaşan hastalıklara ilişkin bilgi formu uygulanmıştır. Yapılan değerlendirme sonucunda öğrenciler eğitim vermek için uygun bulunmuştur.

\section{Ĕ̈itim Broşürünün Geliştirilmesi}

Eğitim broşürünün hazırlık sürecinde öncelikle CYBH konusunda bilgilendirmeye yönelik hedefler belirlenmiş ve bu hedeflere uygun içerik geliştirilmiştir. $\mathrm{Bu}$ amaçla araştırmacılar tarafından CYBH'ye yönelik literatür taranmışs, 13,14, örnek broşürler incelenmiş ve kadın sağlığı alanında uzman üç öğretim üyesinin görüşü alınmıştır.

\section{Araştırmanın Uygulanması}

Araştırmada öncelikle her bir eğitim grubundaki öğrencilere araştırmanın amacı ve metodu anlatılmış ve çalışmaya katılımlarında gönüllülük esas alınmıştır. Eğitim öncesinde her iki eğitim grubundaki öğrencilerin "Katılımcı Tanılama Formu" ve "Cinsel Yolla Bulaşan Hastalıklara İlişkin Bilgi Formu”nu doldurmaları sağlanmıştır. Ayrıca eğitimden bir ay sonra her bir eğitim grubunda "Cinsel Yolla Bulaşan Hastalıklara İlişkin Bilgi Formu” son test olarak tekrar uygulanmıştır.

\section{Akran Ĕgitimi Grubunda Uygulama}

Örneklem kapsamında eğitim verilecek olan 1. sınıf öğrencileri blok randomizasyon yöntemi ile beş gruba ayrılmıştır. Her bir gruba hangi akran eğiticinin eğitim vereceği ise kura çekilerek belirlenmiştir. Her bir akran eğitici, eğitim vereceği grup ile eğitimin zamanını ve yerini eğitim öncesinde belirlemiştir. Daha sonra her bir akran eğitici kendi eğitim grubuna $\mathrm{CYBH}$ konusunda power point sunumu yapmıştır. $\mathrm{Bu}$ eğitimde öğrencilere CYBH'nin önemi, görülme sıklığı, belirtileri, risk grupları ve CYBH'den korunmada yapılması gereken konular anlatılmıştır. Her bir akran eğitimi yaklaşık 60 dakika sürmüştür.

\section{Broşür+Uzman Eğitimi Grubunda Uygulama}

$\mathrm{Bu}$ grupta 2. sınıf öğrencilerin tamamına sorumlu araştırmacı tarafından eğitim broşürü eşliğinde CYBH konusunda eğitim verilmiştir. Bu eğitimin içeriği akran eğitimi ile aynı olup, öğrencilere CYBH'nin önemi, görülme sıklığı, belirtileri, risk grupları ve CYBH'den korunmada yapılması gereken konular anlatılmıştır. Eğitim sonrası öğrencilere okumaları için eğitim broşürü verilmiştir. Bu grupta uygulama yaklaşık 60 dakika sürmüştür. Eğitim, öğrencilerin bireysel hazırlık saatinde, 2. sınıf dersliğinde gerçekleştirilmiştir. 


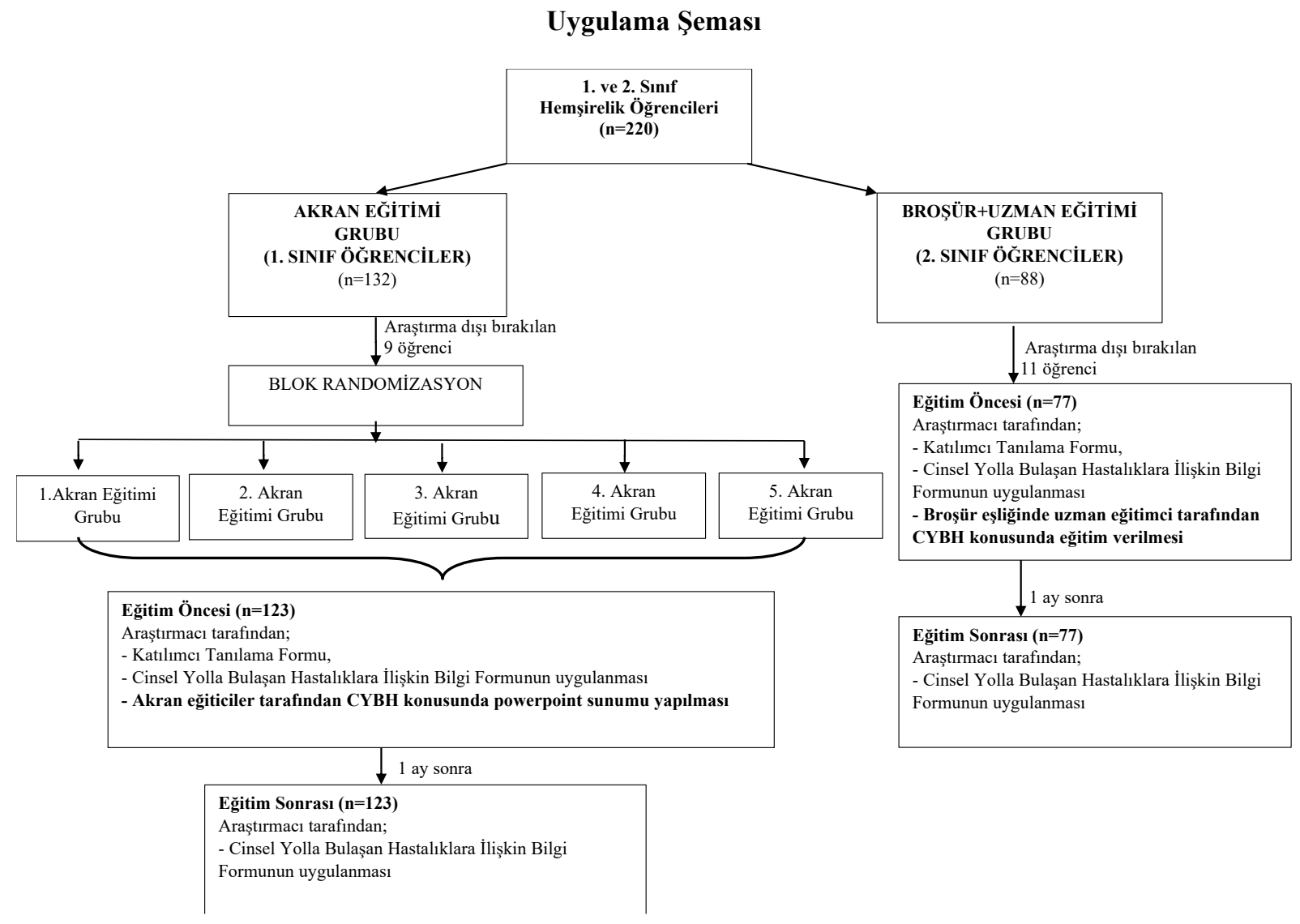

\section{Araştırmanın Etik Boyutu}

Araştırma Helsinki Deklarasyonu prensiplerine uygun olarak yürütülmüş olup, araştırmaya başlamadan önce araştırmanın yürütüldüğü hemşirelik yüksekokulu yönetiminden izin ve kurum etik kurulundan araştırma onayı (etik kurul onay numarası: 1648.4-994) alınmıştır. Daha sonra araştırmaya katılmaya gönüllü olan öğrencilerden onam alınmıştır.

\section{Verilerin Değerlendirilmesi}

Araştırmadan elde edilen verilerin değerlendirilmesinde SPSS for Windows Version 22.0 (IBM Corporation, Armonk, New York, USA) bilgisayar programı kullanılmıştır. Verilerin normal dağılıma uygunlukları tek örnek KolmogorovSmirnov testi ile değerlendirilmiş ve anlamlılık değerleri 0,05 'ten küçük olduğu için ileri düzey çözümlemelerde non-parametrik testler kullanılmıştır. Verilerin dağılımları, kesikli veriler için sayı ve yüzde, sürekli veriler için ortalama \pm standart sapma olarak gösterilmiştir. Karşılaştırmalı istatistiklerde, iki grup arası karşılaştırmalar için Mann Whitney U testi, grup içi önce-sonra karşılaştırmalarında Wilcoxon Signed
Ranks testi kullanılmıştır. Kesikli değişkenlerin istatistiksel karşılaştırılması için Ki-kare testi yapılmıştır. Tüm analizler için yanılma düzeyi 0,05 olarak belirlenmiştir.

\section{BULGULAR}

Öğrencilerin sosyodemografik özelliklerinin dağılımı Tablo 1'de verilmiştir. Çalışma kapsamındaki öğrencilerin yaş ortalaması akran eğitimi grubunda $18,9 \pm 0,3$, broşür+uzman eğitimi grubunda $20,1 \pm 0,3$ 'tür. Her iki eğitim grubundaki öğrencilerin en yüksek oranda çekirdek aile yapısına sahip olduğu saptanmıştır. Akran eğitimi grubundaki öğrencilerin annelerinin \%69,2'sinin ve babalarının \%42,3'ünün, broşür+uzman eğitimi grubundaki öğrencilerin annelerinin \%66,2'sinin ve babalarının \%45,5'inin ilköğretim mezunu olduğu belirlenmiştir. Akran eğitimi grubundaki öğrencilerin \%87'si, broşür+uzman eğitimi grubundaki öğrencilerin \%92,2'si ailelerinin kendilerine karşı çoğunlukla anlayışlı bir tutumlarının olduğunu ifade etmiştir. Yaş, aile tipi, anne eğitim durumu, baba eğitim durumu ve aile tutumu değişkenleri açısından eğitim grupları arasında istatistiksel olarak anlamlı bir fark bulunmamıştır ( $\mathrm{p}>0,05$; Tablo 1$)$. 
Tablo 1. Öğrencilerin sosyodemografik özellikleri

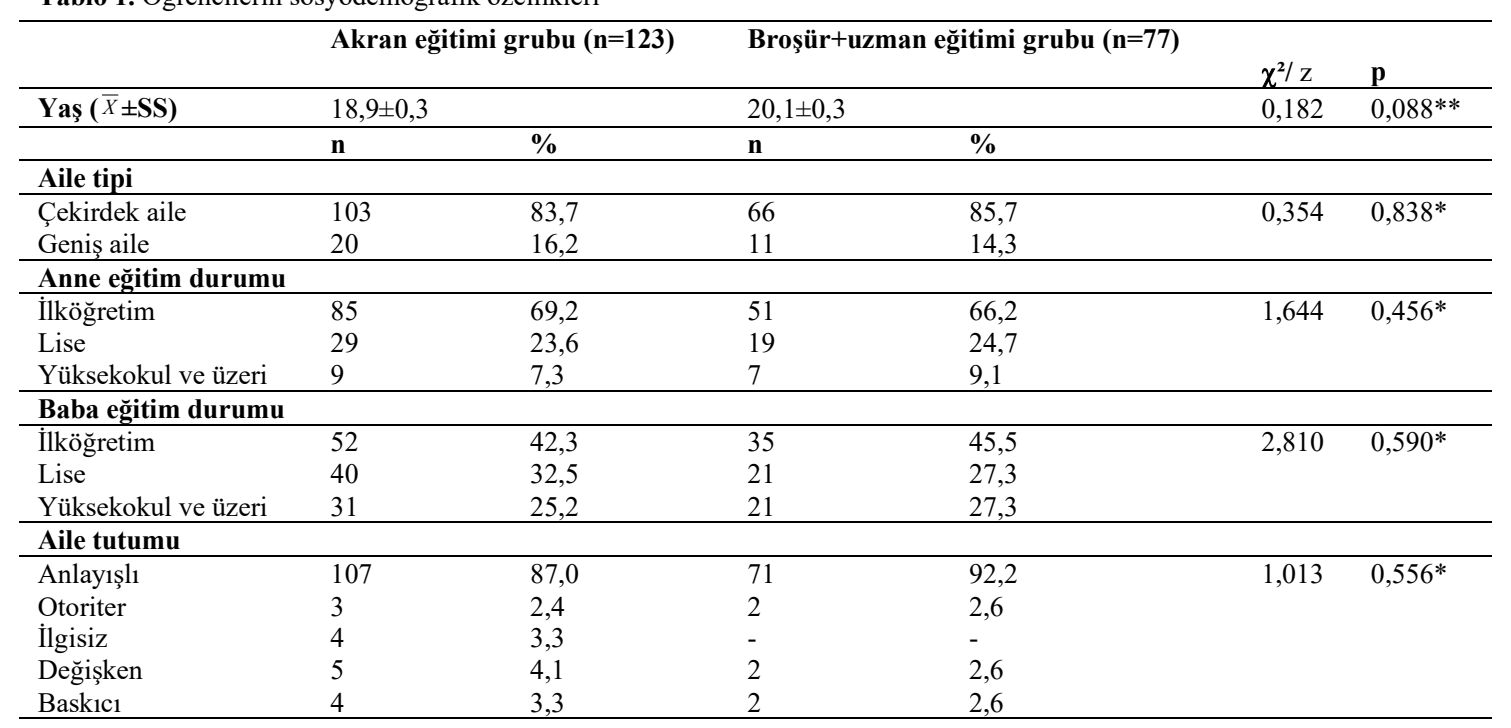

$\bar{X}=$ Ortalama $; S S=$ Standart sapma, $*$ :Ki kare testi, **: Mann Whitney U test $i$

Öğrencilerin eğitim öncesinde CYBH'ye ilişkin bilgileri Tablo 2'de verilmiştir. Eğitim öncesi her iki gruptaki öğrencilerin en yüksek oranda CYBH varlığında görülebilecek belirtilerden vajinal akıntının renginde ve görünümünde değişiklikler olmasını ve cinsel bölgede ya da ağız kenarında ülserasyon, nodül veya kabarcıklar görülebileceğini bildikleri saptanmıştır. Ayrıca her iki eğitim grubundaki öğrencilerin en yüksek oranda CYBH'nin cinsel ilişki dışında kan yolu ile ve anneden bebeğe bulaş olabileceğini bildikleri belirlenmiştir. Eğitim öncesi, akran eğitimi grubundaki öğrenciler CYBH açısından en yüksek oranda çok eşli olan kişilerin risk altında olduğunu ve CYBH'den korunmak için tek eşli olunması gerektiğini belirtmişlerdir. Broşür+uzman eğitimi grubundaki öğrenciler ise $\mathrm{CYBH}$ açısından en yüksek oranda seks işçileri ve cinsel birliktelik yaşadıkları kişilerin risk altında olduğunu ve CYBH'den korunmak için riskli kişilerle ilişkiye girilmemesi gerektiğini ifade etmiştir. CYBH'nin belirtileri, bulaşma yolları, risk faktörleri ve CYBH'den korunma yöntemleri değişkenleri açısından eğitim öncesinde gruplar arasında istatistiksel olarak anlamlı bir fark bulunmamıştır ( $>0$,05; Tablo 2).

Tablo 2. Öğrencilerin eğitim öncesinde cinsel yolla bulaşan hastalıklara ilişkin bilgileri

\begin{tabular}{|c|c|c|c|c|c|c|}
\hline & \multicolumn{2}{|c|}{$\begin{array}{l}\text { Akran eğitimi } \\
\text { grubu }(n=123)\end{array}$} & \multicolumn{2}{|c|}{$\begin{array}{l}\text { Broşür+uzman eğitimi } \\
\text { grubu }(n=77)\end{array}$} & \multirow[t]{2}{*}{$* * \chi^{2}$} & \multirow[t]{2}{*}{$\mathbf{p}$} \\
\hline & $\mathbf{n}$ & $\%$ & $\mathbf{n}$ & $\%$ & & \\
\hline \multicolumn{7}{|l|}{ CYBH belirtilerini bilme durumu* } \\
\hline Ateş & 43 & 35,0 & 43 & 55,8 & 8,427 & 0,051 \\
\hline Cinsel ilişki sırasında ağrı & 44 & 35,8 & 31 & 40,3 & 0,407 & 0,524 \\
\hline Vajinal akıntının renginde ve görünümünde değişiklikler & 90 & 73,2 & 60 & 77,9 & 0,570 & 0,450 \\
\hline $\begin{array}{l}\text { Cinsel bölgede ya da ağız kenarında ülserasyon, nodül veya } \\
\text { kabarcıklar }\end{array}$ & 66 & 53,7 & 47 & 61,0 & 1,050 & 0,306 \\
\hline Cinsel organların etrafinda şişlik & 59 & 48,0 & 34 & 44,2 & 0,277 & 0,599 \\
\hline Genital bölgede yara ve siğil & 59 & 48,0 & 41 & 53,2 & 0,528 & 0,467 \\
\hline Vajinada yanma ya da kaşıntı & 64 & 52,0 & 37 & 48,1 & 0,300 & 0,584 \\
\hline Adet düzensizlikleri/ adet dışı kanama & 55 & 44,7 & 39 & 50,6 & 0,669 & 0,413 \\
\hline Ağrılı idrar yapma & 53 & 43,1 & 31 & 40,3 & 0,156 & 0,693 \\
\hline \multicolumn{7}{|l|}{ CYBH'nin diğer bulaşma yollarını bilme durumu* } \\
\hline Kan yolu ile bulaşma & 100 & 81,3 & 75 & 97,4 & 11,225 & 0,054 \\
\hline Temas ile bulaşma (öpüşmek, tokalaşmak) & 31 & 25,2 & 24 & 29,9 & 0,735 & 0,391 \\
\hline Anneden bebeğe bulaşma & 53 & 43,1 & 53 & 68,8 & 12,597 & 0,052 \\
\hline Bilmiyor & 17 & 13,8 & 2 & 2,6 & 6,939 & 0,057 \\
\hline \multicolumn{7}{|l|}{ CYBH açısından risk altındaki grubu bilme durumu* } \\
\hline Çok eşli olanlar & 96 & 78,0 & 62 & 80,5 & 0,174 & 0,676 \\
\hline Seks işçileri ve cinsel birliktelik yaşadıkları kişiler & 91 & 74,0 & 66 & 85,7 & 3,861 & 0,054 \\
\hline Eşcinseller & 16 & 13,0 & 24 & 31,2 & 4,761 & 0,102 \\
\hline Uyuşturucu bağımlıları & 7 & 5,7 & 12 & 15,6 & 2,391 & 0,120 \\
\hline Bilmiyor & 6 & 4,9 & 1 & 1,3 & 1,796 & 0,059 \\
\hline \multicolumn{7}{|l|}{ CYBH'den korunmak için yapılacakları bilme durumu* } \\
\hline Tek eşlilik & 82 & 66,7 & 57 & 74,0 & 1,210 & 0,271 \\
\hline Riskli kişilerle ilişkiye girmemek & 83 & 67,5 & 58 & 75,3 & 1,401 & 0,237 \\
\hline Kondom (prezervatif) kullanmak & 47 & 38,2 & 38 & 49,4 & 2,404 & 0,121 \\
\hline Bilmiyor & 14 & 11,4 & 2 & 2,6 & 3,965 & 0,051 \\
\hline
\end{tabular}


Tablo 3'de öğrencilerin eğitim öncesi ve eğitim sonrası CYBH'ye ilişkin bilgi puanlarının grup içi ve gruplar arası karşılaştırma sonuçları sunulmuştur. Öğrencilerin eğitim öncesi CYBH konusunda bilgi puan ortalamaları akran eğitimi grubunda 30 puan üzerinden $16,1 \pm 6,6$, broşür+uzman eğitimi grubunda $14,4 \pm 7,3$; eğitim sonrası puan ortalamaları ise sirasıly $24,9 \pm 4,1$ ve 28,5 $\pm 2,4$ olarak hesaplanmıştır. Eğitim gruplarına göre öğrencilerin CYBH konusunda bilgi düzeyleri karşılaştırıldığında; eğitim öncesi CYBH konusunda bilgi puanları açısından gruplar arasında istatistiksel olarak anlamlı bir farklılık bulunmamıştır $(\mathrm{p}>0,05)$. Bununla birlikte öğrencilerin eğitim sonrası $\mathrm{CYBH}$ konusunda bilgi puanlarının eğitim grupları arasında istatistiksel olarak anlamlı derecede farklı olduğu bulunmuştur $(\mathrm{p}<0,001)$. Buna göre broşür+uzman eğitimi verilen öğrencilerin akran eğitimi verilen öğrencilere göre eğitim sonrasında CYBH konusuna ilişkin bilgi düzeylerinin anlamlı derecede daha yüksek olduğu saptanmıştır.

Çalışmada her bir eğitim grubunun kendi içerisinde eğitim öncesi ve eğitim sonrası CYBH'ye ilişkin bilgi düzeyleri de değerlendirilmiştir. Hem akran eğitimi grubunda hem de broşür+uzman eğitimi grubunda CYBH'ye ilişkin bilgi puanları açısından eğitim öncesi ve eğitim sonrası istatistiksel olarak anlamlı bir fark bulunmuştur $(\mathrm{p}<0,001)$. Buna göre her iki eğitim grubundaki öğrencilerin eğitim sonrası CYBH’ye ilişkin bilgi düzeyleri artmıştır (Tablo 3).

Tablo 3. Öğrencilerin eğitim öncesi ve eğitim sonrası cinsel yolla bulaşan hastalıklar konusuna ilişkin bilgi puanlarının karşılaştırma sonuçları

\begin{tabular}{|c|c|c|c|c|c|}
\hline & \multicolumn{2}{|c|}{$\begin{array}{c}\text { Akran eğitimi grubu } \\
(\mathrm{n}=123)\end{array}$} & \multicolumn{3}{|c|}{$\begin{array}{l}\text { Broşür+uzman eğitimi grubu } \\
(n=77)\end{array}$} \\
\hline & $\bar{X}$ & SS & $\overline{\bar{X}}$ & SS & $* * \mathbf{Z} / \mathbf{p}$ \\
\hline $\begin{array}{l}\text { Eğitim öncesi cinsel yolla bulaşan hastalıklara } \\
\text { ilișkin bilgi puanı }\end{array}$ & 16,1 & 6,6 & 14,4 & 7,3 & $1,441 / 0,150$ \\
\hline $\begin{array}{l}\text { Eğitim sonrası cinsel yolla bulaşan hastalıklara } \\
\text { ilişkin bilgi puanı }\end{array}$ & 24,9 & 4,1 & 28,5 & 2,4 & $8,196 /<\mathbf{0 , 0 0 1}$ \\
\hline$*_{\mathbf{z}} / \mathbf{p}$ & \multicolumn{2}{|c|}{$8,950 /<\mathbf{0 , 0 0 1}$} & \multicolumn{3}{|c|}{$7,528 /<\mathbf{0 , 0 0 1}$} \\
\hline
\end{tabular}

\section{TARTIŞMA}

$\mathrm{Bu}$ çalışmada, hemşirelik öğrencilerinin $\mathrm{CYBH}$ konusunda bilgi düzeyleri ve farkındalıklarını arttırmaya yönelik uygulanan akran eğitimi ve broşür+uzman eğitimi yöntemlerinin etkinliği araştırılmıştır. Literatürde hemşirelik öğrencilerinin CYBH ilişkin farkındalık ve bilgi düzeyini arttırmak amacıyla bu iki eğitim yönteminin uygulandığı ve etkinliğinin karşılaştırıldığı benzer bir çalışmaya rastlanmamıştır. $\mathrm{Bu}$ nedenle araştırma sonucunda elde edilen bulgular, farklı öğrenci gruplarının/gençlerin CYBH hastalıklar konusunda bilgi düzeylerinin değerlendirildiği çalışma bulguları ile tartışılmıştır.

Çalışmada her iki eğitim grubundaki öğrencilerin yaş, aile tipi, anne eğitim durumu, baba eğitim durumu ve aile tutumu gibi sosyodemografik özelliklerinin; CYBH'nin belirtileri, bulaşma yolları, risk faktörleri ve CYBH'den korunma yöntemleri gibi CYBH'ye ilişkin bilgilerinin benzer olduğu saptanmıştır. $\mathrm{Bu}$ sonuç $\mathrm{CYBH}$ konusunda bilgi düzeyini arttırmak için eğitimin etkinliğini değerlendirmede grupların homojenliğini göstermesi açısından önemlidir.

Çalışma kapsamında her iki eğitim grubundaki öğrencilerin eğitim öncesi CYBH konusunda bilgi düzeyleri açısından eğitim grupları arasında bir fark yokken; eğitim sonras1 broşür+uzman eğitimi verilen öğrencilerin, akran eğitimi verilen öğrencilere göre CYBH konusunda bilgi düzeylerinin daha yüksek olduğu belirlenmiştir. Bununla birlikte çalışmada her bir eğitim grubundaki öğrencilerin eğitim öncesi CYBH'ye ilişkin bilgi düzeylerinin orta düzeyde olduğu; eğitim sonrası ise hem akran eğitimi grubunda hem de broşür+uzman eğitimi grubunda öğrencilerin bilgi düzeylerinde artış olduğu belirlenmiştir. Kırmızıtoprak ve Şimşek tarafından yapılan çalışmada, CYBH konusunda akran eğiticiler tarafından verilen eğitimin üniversite ögrrencilerinin CYBH'ye ilişkin bilgi düzeylerini arttırmada etkili olduğu bildirilmiştir. ${ }^{17}$ Mahmoud ve Ahmed tarafindan yapılan çalışmada, CYBH konusunda broşür ile eğitim verilen ortaokul öğrencilerinin eğitim sonrası CYBH'ye ilişkin bilgi düzeylerinin arttığı belirlenmiştir. ${ }^{18}$ Ghasemi ve arkadaşları tarafindan yapılan sistematik derlemede CYBH gibi adölesan sağlığına ilişkin konularda çeşitli eğitim yöntemleri kullanılarak (akran, öğretmen, sağllk personeli tarafından ders kapsamında, broşür ve kitapçık gibi materyaller kullanılarak verilen eğitimler) verilen eğitimin adölesanların bilgi düzeylerini arttırmada etkili olduğu bildirilmiştir. Bununla birlikte alanında uzman sağlık personeli tarafından verilen eğitimin akran eğitiminden daha etkili olduğu belirtilmiştir. ${ }^{19}$ $\mathrm{Bu}$ bulgular doğrultusunda herhangi bir yöntemle eğitim vermenin, öğrencilerin $\mathrm{CYBH}$ konusunda bilgi düzeyleri ve farkındalıklarını arttırmada etkili olduğu görülmektedir. $\mathrm{Bu}$ çalışmada diğer çalışmalardan farklı olarak alanında uzman bir 
eğitimci tarafından broşür eşliğinde verilen eğitimin akran eğitimine göre öğrencilerin $\mathrm{CYBH}$ konusunda bilgi düzeyleri ve farkındalıklarını arttırmada daha etkili bir yöntem olduğu saptanmıştır. Bu sonucun, eğitimin hem alanında uzman bir eğitimci tarafından verilmesi hem de eğitim sonrası öğrenciler tarafından broşürün okunması sonucu bilginin daha kalıcı olmasından kaynaklı olabileceği değerlendirilmektedir. Gençlerin CYBH konusunda bilgi düzeyleri ve farkındalıklarını arttırmaya yönelik etkili bir eğitim yönteminin kullanılması, CYBH'nin önlenmesi, riskli cinsel davranışların azalması, cinsel sağlık ve üreme sağlığının korunması ve geliştirilmesi açısından önemlidir.

CYBH'nin çoğundan korunma ve tedavi mümkündür. $\mathrm{Bu}$ nedenle risk altındaki kişilerin tespit edilip, CYBH'den korunmaları için gerekli önlemlerin alınması önemlidir. ${ }^{4}$ Literatürde gençlerin yanı sıra, çok eşli olan, korunmasız cinsel ilişkiye giren, özel cinsel tercihleri olan, seks işçileri ya da birliktelik yaşadıkları kişilerle beraber olan ve uyuşturucu madde kullanan bireylerin CYBH açısından risk altında olduğu bildirilmektedir. . $^{2,3,20}$ $\mathrm{Bu}$ bireylerin CYBH'den korunmasındaki en etkili yöntem ise kondom kullanma ve tek eşli cinsel yaşamdır. ${ }^{4} \mathrm{Bu}$ çalışmada akran eğitimi grubundaki öğrenciler, CYBH açısından en yüksek oranda çok eşli olan kişilerin risk altında olduğunu ve CYBH'den korunmak için tek eşli olunması gerektiğini belirtmişlerdir. Broşür+uzman eğitimi grubundaki öğrenciler ise $\mathrm{CYBH}$ açısından en yüksek oranda seks işçileri ve cinsel birliktelik yaşadıkları kişilerin risk altında olduğunu ve CYBH'den korunmak için riskli kişilerle ilişkiye girilmemesi gerektiğini ifade etmiştir. Elkin tarafından yapılan çalışmada, sağlık bilimleri yüksekokulunda öğrenim gören öğrencilerin, CYBH açısından en yüksek oranda seks işçilerinin ve çok eşli olan kişilerin risk altında olduğunu ve CYBH'den korunmak için riskli kişilerle ilişkiye girilmemesi gerektiğini belirtmişlerdir. ${ }^{21}$ McMann ve Trout tarafından yapılan çalışmada, üniversitede öğrenim gören öğrencilerin en yüksek oranda çok eşli kişilerin $\mathrm{CYBH}$ açısından risk altında olduğunu bildiklerini saptamışlardır. Ayrıca öğrencilerin yarısı, aşı yaptırmanın CYBH'den korunmada etkili olduğunu ifade etmişlerdir. ${ }^{22}$ Folasayo ve arkadaşları tarafından yapılan çalışmada, üniversitede öğrenim gören öğrenciler, çok eşli olmanın CYBH riskini arttırdığını ve CYBH'den korunmak için kondom kullanılması gerektiğini bildirmişlerdir. ${ }^{23}$ Çalışma bulgularımız diğer çalışma sonuçları ile benzerlik göstermektedir. Gençlerin CYBH'lerin risk faktörlerini ve korunma yöntemlerini bilmeleri, riskli cinsel davranışlardan korunmada önemli bir faktördür. Çalışma sonuçları doğrultusunda öğrencilerin CYBH açısından risk altındaki grupları ve buna ilişkin en az bir korunma yöntemini bildikleri ve konuya ilişkin bilgilerinin yeterli olduğu söylenebilir.

CYBH'lerin en önemli belirtisi cinsel organlarda görülen anormal akıntıdır. Bununla birlikte cinsel bölgede veya ağı kenarında ülserasyon, nodül veya kabarcıklar, cinsel organlarda siğil ve uçuklar, kasık bölgesinde lenfadenopati, idrar yaparken yada dışkılama sırasında yanma ve ağrı, yüksek ateş ve genel vücut ağrısı gibi belirtiler de görülebilmektedir. ${ }^{1,4} \mathrm{Bu}$ çalışmada eğitim öncesi her iki eğitim grubundaki öğrencilerin en yüksek oranda $\mathrm{CYBH}$ varlığında görülebilecek belirtilerden vajinal akıntının renginde ve görünümünde değişiklikler olmasını ve cinsel bölgede ya da ağız kenarında ülserasyon, nodül veya kabarcıklar görülebileceğini bildikleri saptanmıştır. McMann ve Trout tarafından yapılan çalışmada, üniversitede öğrenim gören öğrenciler CYBH'de en yüksek oranda cinsel organlarda anormal akıntı, renk değişikliği ve ülser görüldüğünü bildirmişlerdir. ${ }^{22}$ Chaudhry tarafından yapılan çalışmada, tıp fakültesi öğrencilerinin çoğunluğu CYBH'de üretradan enfektif akıntı geldiğini ifade etmişlerdir. ${ }^{24}$ Folasayo ve arkadaşları tarafından yapılan çalışmada ise, üniversitede öğrenim gören öğrenciler CYBH'de yüksek oranda idrar yaparken ağrı olabileceğini belirtmiștir. $^{23} \mathrm{Bu}$ bulgular doğrultusunda öğrencilerin CYBH'lerin en yaygın ve sık görülen belirtilerini bildikleri söylenebilir. Gençlerin CYBH'lerin belirtilerini bilmeleri olası bir hastalık durumunu erken dönemde fark etmeleri ve sağllk kuruluşuna başvurmaları açısından önemlidir. Böylelikle erken tanı ile erken dönemde tedavi mümkün olabilir.

$\mathrm{Bu}$ çalışmada eğitim öncesi her iki eğitim grubundaki öğrencilerin çoğunluğunun CYBH'nin cinsel ilişki dışında kan yolu ile de bulaşabileceğini bildikleri saptanmıştır. Türk ve Bıçakcı tarafından yapılan çalışmada, hemşirelik bölümü 1. sınıf öğrencilerinin çoğu CYBH'nin kan yolu ile de bulaşabileceğini bildirmişlerdir. ${ }^{2}$ Chaudhry tarafından yapılan çalışmada, tıp fakültesinde öğrenim gören öğrenciler CYBH'nin cinsel ilişki dişında en yüksek oranda kan yolu ile bulaşabileceğini ifade etmişlerdir. ${ }^{24}$ Folasayo ve arkadaşları tarafından yapılan çalışmada, üniversitede öğrenim gören öğrenciler CYBH'nin genellikle cinsel ilişki sırasında bulaştığını, cinsel ilişki dışında ise en yüksek oranda enjektörlerin ortak kullanılması sonucunda bulaştığını belirtmişlerdir. ${ }^{23} \mathrm{Bu}$ bulgular doğrultusunda öğrencilerin çoğunluğunun CYBH'nin cinsel ilişki dıșındaki en az bir bulașma yolunu bildikleri söylenebilir. Gençlerin CYBH'nin bulaşma yollarını bilmeleri, bu hastalıklardan korunmak için gerekli önlemleri almalarına olanak sağlayabilir ve böylelikle CYBH'nin yayılma riski azalabilir. 


\section{SONUÇ}

Çalışma kapsamında öğrencilerin CYBH konusunda bilgi düzeylerini arttırmada broşür eşliğinde uzman bir eğitimci tarafından verilen eğitimin akran eğitimine göre daha etkili bir yöntem olduğu saptanmıştır. Eğitim sonrası broşür+uzman eğitimi verilen öğrencilerin akran eğitimi verilen öğrencilere göre $\mathrm{CYBH}$ konusunda bilgi düzeyleri daha yüksektir. Bununla birlikte hem akran eğitimi hem de broşür+uzman eğitimi verilen öğrencilerin eğitim sonrası CYBH'ye ilişkin bilgi düzeyleri eğitim öncesine göre artmıştır. Eğitim öncesinde akran eğitimi grubundaki öğrenciler, CYBH açısından en yüksek oranda çok eşli olan kişilerin risk altında olduğunu ve CYBH'den korunmak için tek eşli olunması gerektiğini bildirmiştir. Broşür+uzman eğitimi grubundaki öğrenciler ise CYBH açısından en yüksek oranda seks işçileri ve cinsel birliktelik yaşadıkları kişilerin risk altında olduğunu ve CYBH'den korunmak için riskli kişilerle ilişkiye girilmemesi gerektiğini ifade etmiştir. Eğitim öncesi her iki eğitim grubundaki öğrencilerin çoğunun CYBH varlığında görülebilecek en az bir belirtiyi ve cinsel ilişki dışında bulaşma yollarından birini bildiği belirlenmiştir. $\mathrm{Bu}$ sonuçlar doğrultusunda gençlere alanında uzman eğitimciler tarafından broşür eşliğinde eğitim verilmesi ve CYBH'lerin risk faktörleri, belirtileri, bulaşma yolları ve CYBH'den korunma yöntemleri konusunda eğitim programları, seminer ve konferansların düzenlenmesi önerilmektedir. Böylelikle gençlerin cinsel sağlık ve üreme sağlığının korunması ve geliştirilmesi sağlanabilir.

Ayrıca bu çalışmada eğitim verilen gençler geleceğin sağlık profesyonellerinden biri olan hemşirelik öğrencilerinden oluşmaktadır. Hemşirelik öğrencilerinin lisans eğitimleri sırasında CYBH konusunda bilgi düzeyleri ve farkındalıklarının arttırılması, öğrencilerin mezun olduklarında bu konuda daha bilinçli olmalarını ve etkin bir hizmet sunmalarını, risk altındaki bireyleri belirleyerek eğitim ve danışmanlık vermelerini sağlayacaktır.

\section{KAYNAKLAR}

1. Mickinzie J. Sexually transmitted diseases. In: Walls R, Hockberger R, Gausche-Hill M. editors. Rosen's Emergency Medicine-Concepts and Clinical Practice E-book. Elsevier Health Sciences;2017. p.1197-1208.

2. Türk R, Bıçakcı H. Hemşirelik bölümü birinci sınıf öğrencilerine verilen cinsel yolla bulaşan hastalıklara ilişkin eğitimin etkinliğinin değerlendirilmesi. JACSD 2018;22-44. doi:10.17367/JACSD.2018.3.4

3. World Health Organization. Sexually transmitted infections (STIs). https://www.who.int/en/news-room/factsheets/detail/sexually-transmitted-infections(stis). Published June 2019. Accessed June 29, 2020.

4. Coşkun AM. Kadın sağlığı ve Hastalıkları Hemşireliği El Kitabı. 2.baskı. İstanbul: Koç Üniversitesi Yayınlar1;2016. p.1-131.

5. Morales A, Espada JP, Orgile M, Escribano S, Johnson BT, Lightfoot M. Interventions to reduce risk for sexually transmitted infections in adolescents: A meta-analysis of trials, 20082016. PloS One 2018;13(6):e0199421. https://doi.org/10.1371/journal

6. Centers for Disease Control and Prevention. STDs in adolescents and young adults. https://www.cdc.gov/std/stats18/adolescents.ht m\#ref2. Published July 2019. Accessed June 30, 2020.

7. Yalnız H, Nebioglu M, Karacan BS, Güven M, Geçici Ö. Madde bağımlılığı tanısı alan gençlerde cinsel yolla bulaşan hastalıklar ve aile planlaması ile ilgili bilgi düzeyi ve verilen eğitimin etkisi. Düşünen Adam Psikiyatri ye Nörolojik Bilimler Dergisi 2011;24(2):106112.doi: 10.5350/DAJPN2011240203

8. Özkan H, Taşğın ZDÜ, Apay SE. Cinsellikle ilgili eğitim alan ve almayan öğrencilerin cinsel sağlık bilgi düzeylerinin karşılaştırılması. Ebelik ve Sağlı Bilimleri Dergisi 2020;3(1):11-21.

9. Abdul R, Gerritsen AAM, Mwangome M, Geubbels E. Prevalence of self-reported symptoms of sexually transmitted infections, knowledge and sexual behaviour among youth in semi-rural Tanzania in the period of adolescent friendly health services strategy implementation. BMC Infect Dis 2018;18(1):229. https://doi.org/10.1186/s12879-018-3138-1

10. Karasu F, Göllüce A, Güvenç E, Dadük S, Tunçel, T. Hemşirelik öğrencilerinin cinsel yolla bulaşan hastalıklar hakkındaki bilgilerinin incelenmesi. İ.Ü. Sağllk Hizmetleri Meslek Yüksek Okulu Dergisi 2017;5(1):1-15.

11. Lale HN. Evlenmek için başvuran çiftlerin aile planlaması ve cinsel yolla bulaşan hastalıklar hakkındaki bilgi ve tutumları [Tıpta Uzmanlık Tezi]. Kayseri, Türkiye: Erciyes Üniversitesi Tıp Fakültesi;2018. p. 1-97.

12. Centers for Disease Control and Prevention. Sexually Transmitted Diseases Treatment Guidelines.

https://www.cdc.gov/std/tg2015/clinical.htm. Published May 2019. Accessed June 30, 2020.

13. Ekşi Z, Kömürcü N. Knowledge level of university students about sexually transmitted diseases. Procedia-Social and Behavioral Sciences 2014;122:465-472. doi: 10.1016/j.sbspro.2014.01.1374 
14. Bell A, Bray L. The knowledge and attitudes of student nurses towards patients with sexually transmitted infections: Exploring changes to the curriculum. Nurse Educ Pract 2014;14:512-517. https://doi.org/10.1016/j.nepr.2014.05.002

15. T.C. Sağlık Bakanlığı Ana Çocuk Sağlığı ve Aile Planlaması Genel Müdürlüğü. Cinsel yolla bulaşan enfeksiyonlar (CYBE/HIV/AIDS) katılımcı kitabı. No: 4-b Ankara:2009. p.1-112.

16. United Nations Fund for Population Activities (UNFPA).Sexually transmitted infections: Breaking the cycle of transmission. New York:2004. p. 1-28.

17. Kırmızıtoprak E, Şimşek Z. Cinsel yolla bulaşan hastalıklar ve güvenli cinsel yaşam konusunda gençlerin bilgi ve davranışlarına akran eğitiminin etkisi. TAF Preventive Medicine Bulletin 2011;10(4):463-472.

18. Mahmoud SF, Ahmed NMES. The effect of providing educational sessions about sexually transmitted diseases on knowledge and attitudes of secondary school students at Zagazig city. J Nurs Educ Pract 2018;8(4):16-27. https://doi.org/10.5430/jnep.v8n4p16

19. Ghasemi V, Simbar M, Fakari FR, Naz, MSG, Kian, Z. The effect of peer education on health promotion of Iranian adolescents: A systematic review. Int J Pediatr 2019;7(3):9139-9157. doi: 10.22038/ijp.2018.36143.3153
20. Bajaj S, et al. Risk factors for sexually transmitted diseases in Canada and provincial variations. Social Medicine 2017;11(2):62-69.

21. Elkin N. Üniversite öğrencilerinin cinsel yolla bulaşan hastalıklar konusundaki bilgilerinin araştırılması. Mersin Üniversitesi Sağlık Bilimleri Dergisi 2015;8(1):1-14.

22. McMann N, Trout KE. Assessing the knowledge, attitudes, and practices regarding sexually transmitted infections among college students in a rural midwest setting. J Community Health 2020;1-10. https://doi.org/10.1007/s10900-020-00855-3

23. Folasayo AT, Oluwasegun AJ, Samsudin S, Saudi SNS, Osman M, Hamat RA. Assessing the knowledge level, attitudes, risky behaviors and preventive practices on sexually transmitted diseases among university students as future healthcare providers in the central zone of Malaysia: A cross-sectional study. Int J Environ Res Public Health 2017;14(2):159. doi:10.3390/ijerph14020159

24. Chaudhry R. Knowledge about and attitude towards sexually transmitted diseases, amongst first year medical students of continental medical college Lahore. J Pak Med Assoc 2017;11(4):1574-1578. 